\title{
Dentin bond durability and water sorption/solubility of one-step self-etch adhesives
}

\author{
Shima ITOH ${ }^{1}$, Masatoshi NAKAJIMA ${ }^{1}$, Keiichi HOSAKA ${ }^{1}$, Masako OKUMA ${ }^{1}$, Masahiro TAKAHASHI ${ }^{1}$, Yuko SHINODA ${ }^{1}$, \\ Naoko SEKI ${ }^{1}$, Masaomi IKEDA², Ryuzo KISHIKAWA ${ }^{1}$, Richard M. FOXTON ${ }^{3}$ and Junji TAGAMI ${ }^{1,4}$ \\ ${ }^{1}$ Cariology and Operative Dentistry, Department of Restorative Sciences, Graduate School of Medical and Dental Sciences, Tokyo Medical and \\ Dental University, 1-5-45 Yushima, Bunkyo-ku, Tokyo 113-8549, Japan \\ ${ }^{2}$ Faculty of Dentistry, School for Dental Technology, Tokyo Medical and Dental University, 1-5-45 Yushima, Bunkyo-ku, Tokyo 113-8549, Japan \\ ${ }^{3}$ Department of Conservative Dentistry, King's College London Dental Institute at Guy's, King's and St Thomas' Hospitals, King's College London, \\ London Bridge, London SE1-9RT, UK \\ ${ }^{4}$ Global Center of Excellence Program; International Research Center for Molecular Science in Tooth and Bone Diseases at Tokyo Medical and \\ Dental University, 1-5-45 Yushima, Bunkyo-ku, Tokyo 113-8549, Japan \\ Corresponding author, Shima ITOH; E-mail: shima.itoh@gmail.com
}

\begin{abstract}
The purpose of this study was to evaluate the dentin bonding durability of three HEMA-containing one-step self-etch adhesives after one-year water storage and to measure the amounts of their water sorption/solubility. OptiBond All-In-One (OP), Bond Force (BF) and Clearfil $\mathrm{S}^{3}$ Bond $\left(\mathrm{S}^{3}\right)$ were applied to the dentin surfaces according to manufacturers' instructions. Bond strengths to dentin were determined using $\mu$ TBS test after water storage for 24 hours, six months, and one year. In addition, water sorption and solubility of the polymerized adhesives were measured. The $\mu \mathrm{TBS}$ of $\mathrm{S}^{3}$ and OP significantly decreased after one year. On the other hand, for BF there were no significant differences in $\mu$ TBS between all storage periods. There were significant differences in water sorption and solubility among the adhesives $\left(\mathrm{BF}>\mathrm{S}^{3}>\mathrm{OP}\right)$. The initial amounts of water sorption and solubility of the three adhesives did not affect their bonding durability to dentin.
\end{abstract}

Keywords: One-step self-etch adhesives, Dentin bonding durability, Water sorption/solubility

\section{INTRODUCTION}

The durability of the resin-dentin bond is one of the important factors in maintaining the integrity of adhesive restorations. In the case of etch-and-rinse adhesive systems, discrepancies between the depth of demineralization and resin infiltration may create three-dimensional leakage pathways through nanometer-sized channels within the hybrid layer, an observation, which has been called "nanoleakage"1). Leakage within the hybrid layer permits water movement which may accelerate the plasticization of adhesive resins and hydrolysis of exposed collagen within the hybrid layer, resulting in degradation of the hybrid layer ${ }^{2,3)}$. With self-etch adhesives, it has been generally accepted that there are fewer discrepancies between the demineralized dentin and infiltrated resin monomer because demineralization and resin monomer infiltration occur simultaneously ${ }^{4}$. However, in our previous study using two-step self-etch adhesives, it was found that nanoleakage gradually increased within the hybrid layer over time, leading to a reduction in dentin bond strength and specimen failures within the hybrid layer ${ }^{5)}$.

On the other hand, the dentin bond strengths of one-step self-etch adhesives have been reported to reduce after long-term water storage ${ }^{6-8)}$, with an associated increase in the number of cohesive failures in adhesive resin ${ }^{7)}$. The majority of one-step self-etch adhesives contain ionic resin monomers with acidic phosphate or carboxylic functional groups, hydrophilic monomers, hydrophobic monomers, water and organic solvents in a single bottle ${ }^{9,10)}$. As a result, these adhesives are highly hydrophilic. The hydrophilic nature of these adhesive blends depends on the number of acidic and highly polar functional groups substituted with the methacrylate monomers. It has been shown that the hydrophilicity of adhesives is related to water sorption into the adhesive polymers ${ }^{11-14)}$. According to these studies, the more hydrophilic the adhesives are, the more water their polymers absorb.

Water absorbed into the adhesive polymers also results in polymer swelling, plasticising ${ }^{11,13)}$, a reduction in glass transition temperature ${ }^{15)}$ and a weakening of the polymer network ${ }^{11,16}$. These adhesive polymers have been shown to act as semi-permeable membranes, permitting water movement across the adhesive layer even after polymerisation ${ }^{17)}$, leading to a deterioration in their mechanical properties ${ }^{16,18}$. Therefore, the amount of water sorption in a one-step self-etch adhesive might contribute to an accelerated degradation of its adhesive interface to dentin after long-term water storage. However, there have been few studies on the influence of the amount of water sorption in one-step self-etch adhesives on the durability of the resin-dentin bond. As such, the relationship between the bonding durability of one-step self-etch adhesives to dentin and water sorption is still unclear.

Moreover, the hydrophilic monomer, HEMA, in various concentrations is frequently added to one-step self-etch adhesives because of its positive influence on adhesion to dentin ${ }^{19}$, the miscibility of hydrophobic and 
hydrophilic components in the adhesive blend ${ }^{20-22)}$ and prevention of phase separation ${ }^{21,23)}$. However, HEMA (i.e. poly-HEMA) attracts water even after polymerization $^{11)}$. Therefore, higher concentrations of HEMA might compromise the long-term stability of resin-dentin interface.

The objective of this study was to investigate the $\mu$ TBS to dentin of three HEMA-containing one-step self-etch adhesives after immersion in water for 24 hours, 6 months and 1 year and to measure their initial amounts of water sorption and solubility. The null hypotheses tested were that 1 year of water storage does not affect the $\mu$ TBS of one-step self-etch adhesives to dentin and that water sorption is not affected by one-step self-etch adhesives of different manufacturers.

\section{MATERIALS AND METHODS}

Three commercially available HEMA-containing onestep self-etch adhesives, OptiBond All-In-One (OP; Kerr, Orange, CA), Bond Force (BF; Tokuyama Dental Corp., Tokyo, Japan) and Clearfil $\mathrm{S}^{3}$ Bond ( $\mathrm{S}^{3}$; Kuraray Medical Inc., Tokyo, Japan) were used in this study.

\section{Teeth preparation}

Eighteen caries-free extracted human third molars stored frozen were used in this study, according to the protocol approved by the Human Research Ethics Committee, Tokyo Medical and Dental University, Japan. After removal of the occlusal enamel, each surface was ground with 600-grit SiC paper under running water to obtain flat coronal dentin surfaces. The specimens were then randomly divided into three groups. Three one-step self-etch adhesives (OP, BF and $\mathrm{S}^{3}$ ) were applied to the dentin surfaces according to manufacturers' instructions (Table 1).

After polymerization of the adhesives using a lightcuring unit (XL3000, 3M ESPE, St. Paul, MN, USA) with an intensity of $600 \mathrm{~mW} / \mathrm{cm}^{2}$, the crowns were built up incrementally in three layers with Clearfil AP-X (Kuraray Medical Inc., Tokyo, Japan) to a height of between 4 and $5 \mathrm{~mm}$. Each layer was light-cured for 20 seconds. The bonded assemblies were stored in tap water at $37^{\circ} \mathrm{C}$ for 24 hours. After storage, each bonded tooth was serially sectioned into $0.7 \mathrm{~mm}$ thick slabs using a low speed diamond saw (Leitz 1600 Microtome, Leica Instruments GmbH, Heidelberg, Germany) under water-cooling. Five slabs per tooth could be harvested for testing. The adhesive-dentin interface was trimmed into an hour-glass shape with a $1 \mathrm{~mm}^{2}$ cross-sectional area $(0.7 \times 1.4 \mathrm{~mm})$, using a superfine diamond point (SF114, Shofu Inc., Kyoto, Japan) mounted in a highspeed turbine handpiece under copious water spray. The specimens were randomly divided into two experimental groups and a 24-hours group (control group). The specimens of the two experimental groups were stored in tap water at $37^{\circ} \mathrm{C}$ for 6 months or 1 year individually. The water in which the slabs were stored was changed weekly until testing.

\section{Micro-tensile bond strength test}

After the designated period's storage, the specimens were individually bonded to a jig using a cyanoacrylate adhesive (Zapit, Dental Ventures of America, CA, USA) mounted in a tabletop testing machine (EZ Test, Shimadzu Co., Kyoto, Japan) and subjected to the micro-tensile bond strength ( $\mu$ TBS) test at a crosshead speed of $1.0 \mathrm{~mm} / \mathrm{min}$ (Fig. 1).

\section{Failure mode analysis}

The fractured specimens were mounted on brass stubs, gold sputter-coated and observed using scanning electron microscopy (SEM) (JSM-5310, JEOL, Tokyo, Japan). The mode of failure was classified as either: (1) C-D; cohesive failure in dentin, (2) C-R; cohesive failure in resin and (3) I-F; interfacial failure.

Table 1 Chemical composition and application mode of the materials tested in this study

\begin{tabular}{|c|c|c|}
\hline Materials & Composition & Procedures \\
\hline $\begin{array}{l}\text { OptiBond All-In-One } \\
\text { (OP; Kerr) } \\
\mathrm{pH}=2.5\end{array}$ & $\begin{array}{l}\text { GPDM, GDM, HEMA, Bis-GMA, } \\
\text { water, ethanol, acetone, silica filler, } \\
\text { CQ, sodium hexafluorosilicate }\end{array}$ & $\begin{array}{l}\text { Shake the bottle briefly } \\
\text { Apply two coats with agitation for } 20 \mathrm{~s} \text { each } \\
\text { Dry with medium air pressure after gentle air } \\
\text { pressure for } 5 \mathrm{~s} \\
\text { Light cure for } 10 \mathrm{~s}\end{array}$ \\
\hline $\begin{array}{l}\text { Bond Force } \\
\text { (BF; Tokuyama) } \\
\mathrm{pH}=2.3\end{array}$ & $\begin{array}{l}\text { Methacryloyloxyalkyl acid phosphate, } \\
\text { HEMA, Bis-GMA, TEGDMA, water, } \\
\text { isopropyl alcohol, Glass Filler, CQ }\end{array}$ & $\begin{array}{l}\text { Apply for } 20 \mathrm{~s} \\
\text { Dry with moderate, strong air pressure for } 5 \mathrm{~s} \\
\text { after weak air pressure for } 5 \mathrm{~s} \\
\text { Light cure for } 10 \mathrm{~s}\end{array}$ \\
\hline $\begin{array}{l}\text { Clearfil } \mathrm{S}^{3} \text { Bond } \\
\left(\mathrm{S}^{3} ; \text { Kuraray Medical }\right) \\
\mathrm{pH}=2.7\end{array}$ & $\begin{array}{l}\text { 10-MDP, HEMA, Bis-GMA, water, } \\
\text { ethanol, silanated colloidal silica, CQ }\end{array}$ & $\begin{array}{l}\text { Apply for } 20 \mathrm{~s} \\
\text { Dry with strong air pressure for } 5 \mathrm{~s} \\
\text { Light cure for } 10 \mathrm{~s}\end{array}$ \\
\hline
\end{tabular}

Abbreviations: HEMA: 2-hydroxyethyl methacrylate; Bis-GMA: bisphenol-A-diglycidyl methacrylate; TEGDMA: triethyleneglycol dimethacrylate; CQ: camphorquinone; 10-MDP: 10-methacryloyloxydecyl dihydrogen phosphate; GPDM: glycerol phosphate dimethacrylate and GDM: glycerol dimethacrylate 


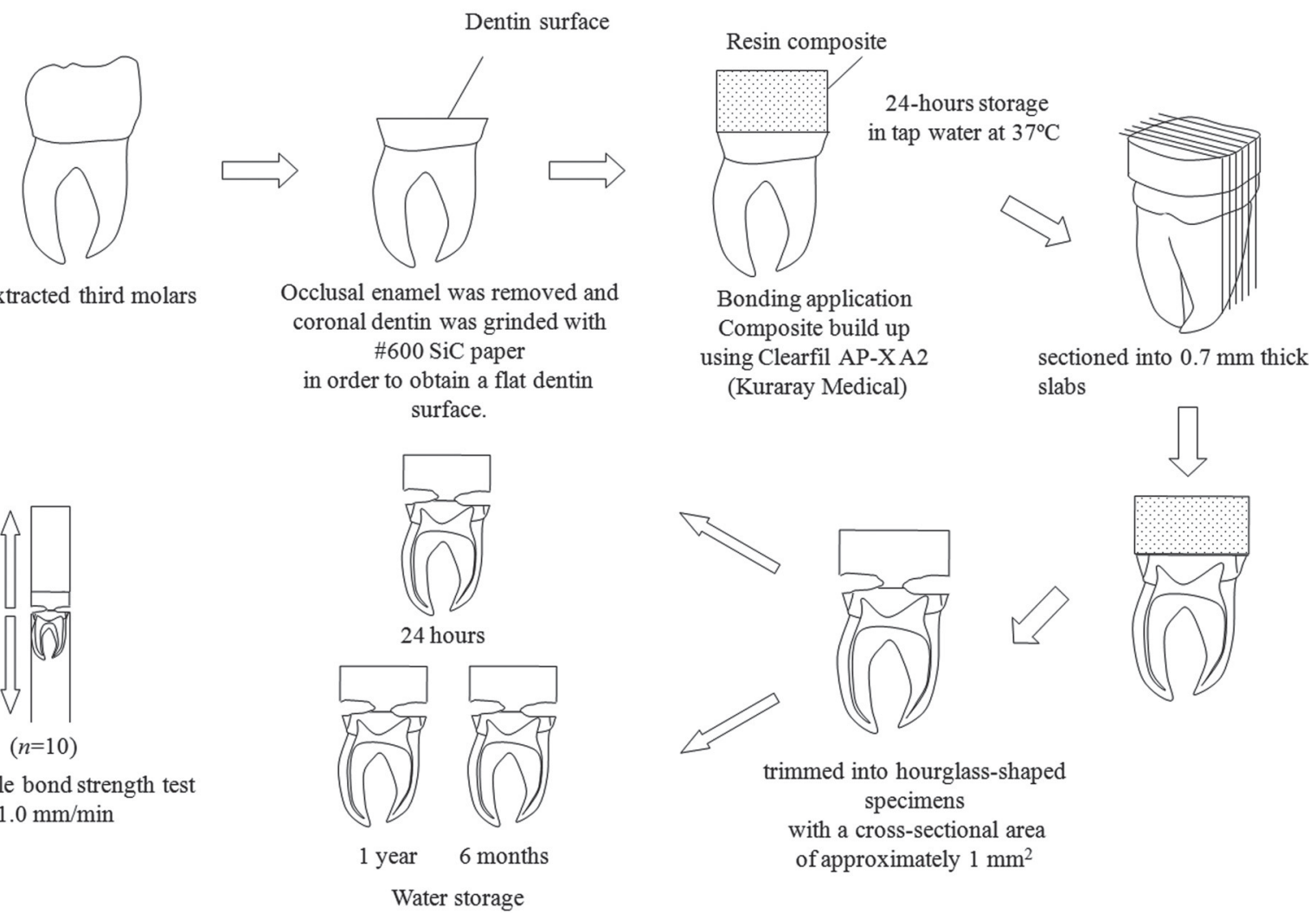

Fig. 1 Schematic illustration of specimen preparation, water storage and micro-tensile bond strength test.

Interfacial failure was defined as regions between the top of hybrid layer and the bottom of hybrid layer. The area ratios of each failure mode on the dentin sides were expressed as percentages per overall fractured surface on the SEM micrographs by digitizing and subjecting them to quantitative image analysis using SemAfore software (Insinööritoimisto, J. Rimppi Oy, Finland).

\section{Measurement of water sorption and solubility}

One milliliter of each adhesive was placed in a tarred, wide, round and flat container $(9.0 \mathrm{~cm}$ in diameter). In subdued light, the solvents of each adhesive were evaporated with a three-in-one dental air-syringe for 10 minutes at a distance of $15 \mathrm{~cm}$ at air pressure of 3.8 $\mathrm{kgf} \mathrm{cm}^{-2}$ until the container stopped losing weight on an electronic analytical balance (Model GR-202, A\&D Co., Tokyo, Japan). When the mixture reached a constant mass, solvent evaporation was assumed to be complete. The co-monomer mixture was poured into round-shaped molds (7.2 $\mathrm{mm}$ in diameter and $3.0 \mathrm{~mm}$ in thick.) These were positioned on glass slabs and covered by transparent thin film (KerrHawe Striproll, KerrHawe, Bioggio, Switzerland) and another glass slab. The adhesive in these molds was irradiated for 90 seconds using a light-curing unit (XL3000, 3M ESPE, St. Paul, $\mathrm{MN}$, USA) with an intensity of $600 \mathrm{~mW} / \mathrm{cm}^{2}$ and then the glass slab and film were carefully peeled away. After removing the disks from the mold, the bottom of each disk was cured for another 90 seconds. Water sorption and solubility were determined according to the ISO specification 4049 (2000), except for disks' dimensions and period of water immersion. The number of resin disks was ten for each adhesive.

Immediately after polymerization, the specimens were placed in a container filled with anhydrous calcium sulphate $\left(\mathrm{CaSO}_{4}\right)$ to ensure dryness at $37^{\circ} \mathrm{C}$. The specimens were repeatedly weighed after intervals of 24 hours until a constant mass $\left(M_{1}\right)$ was obtained. The thickness and diameter of the specimens were measured using a digital caliper (ABS Solar Digimatic Caliper, Mitutoyo Co., Kanagawa, Japan) rounded to the nearest $0.01 \mathrm{~mm}$, and these measurements were used to calculate the volume $(V)$ of each specimen (in $\mathrm{mm}^{3}$ ). They were individually immersed in distilled water at $37^{\circ} \mathrm{C}$ for the water sorption and solubility test. After intervals of 24 hours, the resin disks were gently wiped with absorbent paper, weighed, and stored in distilled water. This regime was continued until a constant mass $\left(M_{2}\right)$ was obtained. Then, the resin disks were stored in a dry state, and weighed daily until a constant dry mass $\left(M_{3}\right)$ was obtained. Water sorption $(W S)$ and solubility $(S L)$ were calculated using the following formulae: 


$$
\begin{aligned}
& W S=M_{2}-M_{3} / V \\
& S L=M_{1}-M_{3} / V
\end{aligned}
$$

where $M_{1}$ is the initial dry constant mass $(\mu \mathrm{g})$ before water storage; $M_{2}$ is the wet constant mass $(\mu \mathrm{g})$ after water storage; $M_{3}$ is the dry constant mass after desiccation and $V$ is the volume of the specimen in $\mathrm{mm}^{3}$.

\section{Statistical analyses}

Bond strength values were calculated in $\mathrm{MPa}$ and statistically analyzed using two- and one-way ANOVAs with the Dunnett's T3 post-hoc multiple comparison test to identify significant differences induced by the periods of water storage among the adhesive systems at a $95 \%$ level of confidence.

The percentages of each failure mode of each adhesive system between all the three storage periods were statistically analyzed using Kruskal-Wallis oneway ANOVA $(p<0.05)$ and the Mann-Whitney U-tests combined with the Bonferroni correction $(p<0.016)$.

The $W S$ and $S L$ data were analyzed using two individual one-way ANOVAs seeking for significant differences among the adhesive systems. Additionally, Dunnett's T3 test was used for post-hoc multiple comparisons at a $95 \%$ level of confidence.

\section{RESULTS}

Table 2 shows the mean bond strengths of the three one-step self-etch adhesives to dentin as a function of the water-storage period. Two-way ANOVA revealed that the adhesive system $(p=0.0001)$ and storage period $(p=0.002)$ significantly affected the $\mu$ TBS. In addition, there was no significant interaction between the adhesive system and storage period $(p=0.729)$. Oneway ANOVA revealed that the $\mu$ TBS of OP and $\mathrm{S}^{3}$ were significantly affected by the storage periods (OP; $p=0.043$ and $\left.\mathrm{S}^{3} ; p=0.023\right)$, while for $\mathrm{BF}$ there was no significant difference between the storage periods $(p=0.261)$ although the $\mu$ TBS decreased over time. One-year of water storage significantly reduced the $\mu$ TBS of $\mathrm{S}^{3}$ and OP compared with the 24-hour and the 6 -month storage periods, respectively $(p<0.05)$. There were no significant differences in the $\mu$ TBS to dentin among the three adhesives at the 24-hour and 1-year periods $(p>0.05)$.

The percentage of the failure modes are summarized in Figure 2. For OP and $\mathrm{S}^{3}$, the KruskalWallis test indicated significant increases in the percentage of cohesive failures in resin (C-R) (OP; $p=0.003$ and $\mathrm{S}^{3} ; p=0.02$ ) and significant decreases in the percentage of interfacial failures (I-F) (OP; $p=0.008$ and $\left.\mathrm{S}^{3} ; p=0.028\right)$. For $\mathrm{BF}$, there were no significant differences among the storage periods for each failure mode (C-R; $p=0.13$, I-F; $p=0.074$ and C-D; $p=0.461$ ), although the percentage of $\mathrm{C}-\mathrm{R}$ increased and the percentage of I-F decreased after 1 year of water storage compared to 24 hours of storage.

Figures 3 and 4 are scanning electron micrograph pictures in the regions of cohesive failure in resin of the de-bonded specimens after 24 hours and 1 year of water storage. After 24 hours of water storage, BF showed numerous pores within the adhesive layer, while OP and $\mathrm{S}^{3}$ showed no porosity in the adhesive layer. After 1 year of water storage, all three one-step adhesives failed within the adhesive layer and/or in the adhesive-composite interface, in which filler particles were observed to have detached or were missing.

The water sorption (WS) and solubility $(S L)$ of the

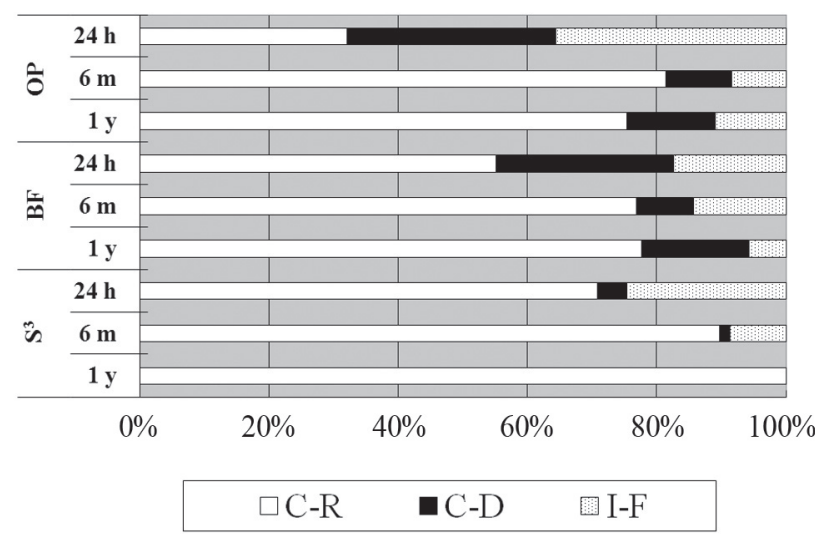

Fig. 2 Percentages of failure modes of three one-step self-etch adhesives. C-R: cohesive failure in resin, C-D: cohesive failure in dentin and I-F: interfacial failure between the top of hybrid layer and the bottom of hybrid layer.

\begin{tabular}{|c|c|c|c|}
\hline Time & $\begin{array}{l}\text { OptiBond All-In-One } \\
\qquad(\mathrm{MPa})\end{array}$ & $\begin{array}{l}\text { Bond Force } \\
\text { (MPa) }\end{array}$ & $\begin{array}{c}\text { Clearfil } \mathrm{S}^{3} \text { Bond } \\
(\mathrm{MPa})\end{array}$ \\
\hline 24 hours & $47.6(10.0)^{\mathrm{AB} ; 1}$ & $48.8(12.7)^{\mathrm{A} ; 1}$ & $40.1(3.2)^{\mathrm{A} ; 1}$ \\
\hline 6 months & $49.0(8.8)^{\mathrm{A} ; 1}$ & $45.4(9.7)^{\mathrm{A} ; 1}$ & $36.6(4.3)^{\mathrm{AB} ; 2}$ \\
\hline 1 year & $39.1(8.0)^{\mathrm{B} ; 1}$ & $41.0(8.3)^{\mathrm{A} ; 1}$ & $33.5(6.8)^{\mathrm{B} ; 1}$ \\
\hline
\end{tabular}

Table 2 Micro-tensile bond strengths of the three one-step self-etch adhesives tested in this study

Values are means (standard deviations). $n=10$ (per group). Different superscript letters in each column indicate statistically significant differences among storage periods $(p<0.05)$. Different superscript numbers in each row indicate statistically significant differences among the adhesive systems $(p<0.05)$. 


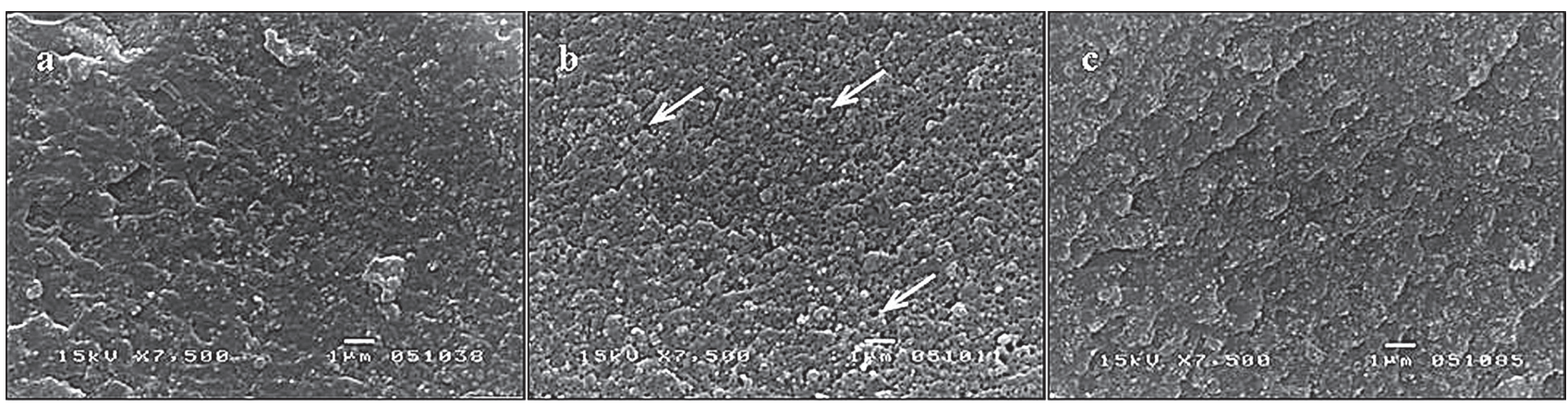

Fig. 3 Representative SEM images in the regions of cohesive failure in resin of the de-bonded specimens after 24 hours of water storage. (a) OptiBond All-In-One, (b) Bond Force; Numerous pores (white arrows) were observed within the adhesives and (c) Clearfil $\mathrm{S}^{3}$ Bond.
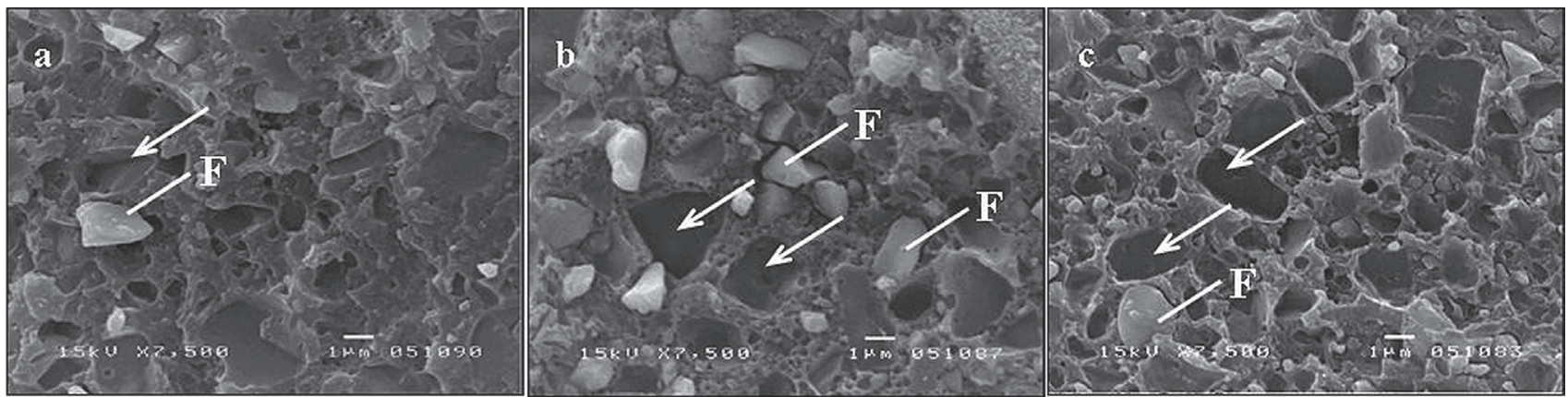

Fig. 4 Representative SEM images in the regions of cohesive failure in resin of the de-bonded specimens after 1 year of water storage. (a) OptiBond All-In-One, (b) Bond Force and (c) Clearfil S ${ }^{3}$ Bond. All three one-step adhesives failed within the adhesive layer and/or in the adhesive-composite interface, in which filler particles were observed to have detached $(\mathrm{F})$ or were missing (white arrows).

Table 3 The amounts of initial water sorption and solubility of one-step self-etch adhesive polymers

\begin{tabular}{lcc}
\hline Adhesives & $\begin{array}{c}\text { Water sorption } \\
\left(\mu \mathrm{g} / \mathrm{mm}^{3}\right)\end{array}$ & $\begin{array}{c}\text { Solubility } \\
\left(\mu \mathrm{g} / \mathrm{mm}^{3}\right)\end{array}$ \\
\hline OptiBond All-In-One & $110.7(2.2)^{\mathrm{A}}$ & $7.8(2.1)^{\mathrm{A}}$ \\
Bond Force & $163.3(3.5)^{\mathrm{B}}$ & $15.6(0.8)^{\mathrm{B}}$ \\
Clearfil S ${ }^{3}$ Bond & $148.6(3.6)^{\mathrm{C}}$ & $12.7(1.0)^{\mathrm{C}}$ \\
\hline
\end{tabular}

Values are means (standard deviations). $n=10$ (per group). Different superscript letters in each column indicate statistically significant differences among the adhesive systems $(p<0.05)$.

three one-step self-etch adhesives are summarized in Table 3. One-way ANOVA revealed that the WS and $S L$ were influenced by the adhesive system (WS; $p=0.0001$ and $S L ; p=0.0001)$. There were significant differences in water sorption and solubility between all the adhesives $(p<0.05)$. The values for both water sorption and solubility were seen in the order of $\mathrm{BF}>\mathrm{S}^{3}>\mathrm{OP}$.

\section{DISCUSSION}

In the present study, the tested HEMA-containing onestep self-adhesives showed different amounts of water sorption. The results of this study require rejection of the null hypothesis that water sorption is not affected by one-step self-etch adhesives of different manufacturers. Many factors may affect the water sorption of polymerized one-step self-etch adhesives, such as the hydrophilic and hydrophobic monomers within the adhesives ${ }^{24)}$, other polar constituents ${ }^{11)}$, and 
the presence and type of filler particles ${ }^{25}$. In particular, the presence of HEMA, a hydrophilic monomer, will strongly affect water sorption. It was reported that the amount of water sorption of adhesive polymers increased proportionally to their HEMA concentrations ${ }^{14}$, therefore the water sorption results might be dependent upon the HEMA concentrations of the tested one-step self-etch adhesives.

Moreover, the solvents are probably another factor regarding the extent of water sorption ${ }^{13)}$. In this study, the highest water sorption values were obtained in BF $\left(163.3 \mu \mathrm{g} / \mathrm{mm}^{3}\right)$, followed by $\mathrm{S}^{3}\left(148.6 \mu \mathrm{g} / \mathrm{mm}^{3}\right)$ and OP $\left(110.7 \mu \mathrm{g} / \mathrm{mm}^{3}\right)$, in which there were statistically significant differences among all three adhesives $(p<0.05)$. Many constituents of one-step selfetch adhesives are dissolved in water and organic solvents. The tested one-step self-etch adhesives utilize different types of solvents (OP: acetone and ethanol, BF: isopropyl alcohol, $\mathrm{S}^{3}$ : ethanol). Recent studies have indicated that both acetone and ethanol evaporate faster than water because they have higher vapor pressures ${ }^{26,27)}$. Their evaporation increases the concentration of monomers in the adhesives ${ }^{26)}$, which lowers the vapor pressure of the remaining residual solvents, making it impossible to evaporate all solvent during air-drying stage ${ }^{26)}$. The omission of HEMA in the adhesive formulation of the one-step self-etch adhesives, separating water from the other ingredients upon ethanol/acetone evaporation, may be advantageous in removing most of the water ${ }^{21}$. However, it might be difficult to evaporate all water from phase-separated adhesive even with very strong air-drying under identical clinical conditions, because of the low vapor pressure of water ${ }^{21}$. On the other hand, for HEMAcontaining adhesives such as those used in this study, residual water in the co-monomer mixtures would be attracted by poly-HEMA and/or other polymers leading to an increase in the free volume of polymerized adhesive, which promotes water sorption into the polymerized adhesive even after drying prior to water immersion. On the other hand, any residual solvent remaining after air-drying might produce defects within the polymerized adhesive, which would be replaced by water during water immersion. Of the three tested adhesives in the present study, pores were detected in the SEM images of BF after 24 hours. The vapor pressure (at $25^{\circ} \mathrm{C}$ ) is $44 \mathrm{~mm} \mathrm{Hg}$ for isopropyl alcohol, $200 \mathrm{~mm} \mathrm{Hg}$ for acetone and $54.1 \mathrm{~mm} \mathrm{Hg}$ for ethanol. These indicate that isopropyl alcohol makes it more difficult to evaporate by air-drying than acetone and ethanol. Therefore, in the case of $\mathrm{BF}$, the solvent (isopropyl alcohol) may not have been completely removed by air-drying. Water molecules diffuse through pores in the material without mutual relationship to the polar sites of the material ${ }^{28}$. The water sorption in $\mathrm{BF}$ might therefore have been due to pore formation within the polymerized adhesive caused by the presence of residual solvent.

Water sorption is known to be associated with water solubility ${ }^{14)}$. The solubility of adhesive polymers represents the amount of water-soluble ingredients ${ }^{29}$. Unpolymerized monomers or oligomers can leach out of the polymer during water immersion and subsequent polymer expansion ${ }^{14)}$. After entering the polymer, water triggers hydrolysis, resulting in the elution of filler particles and ions and the deterioration of adhesive polymers over time ${ }^{29}$. A higher water sorption value might be related to higher solubility. Indeed, $\mathrm{BF}$ showed the highest solubility $\left(15.6 \mu \mathrm{g} / \mathrm{mm}^{3}\right)$ and the highest water sorption $\left(163.3 \mu \mathrm{g} / \mathrm{mm}^{3}\right)$ among the three adhesive systems. Increased water sorption in adhesive polymers might increase the risk of deterioration of the one-step self-etch adhesive layer after long-term water storage.

The $\mu$ TBS results of this study partially require rejection of the null hypothesis that 1 year of water storage does not affect the $\mu$ TBS of one-step self-etch adhesives to dentin. In this study, the $\mu$ TBS of OP and $\mathrm{S}^{3}$ were significantly affected by the storage periods. Moreover, the failure mode analyses of OP and $\mathrm{S}^{3}$ after 1 year of water storage revealed that the percentage of cohesive failures in resin (C-R) significantly increased, while the percentage of interfacial failures (I-F) significantly decreased (Fig. 2). These findings indicate that the degraded adhesive polymers caused reductions in $\mu$ TBS over time and are in agreement with previous studies using one-step self-etch adhesives ${ }^{6,77}$. It has been suggested that the reduction in dentin bonding durability of one-step self-etch adhesives was due to a deterioration of the adhesive layer by water infiltration. On the other hand, BF, which had the highest water sorption and solubility values showed no significant reduction of $\mu$ TBS to dentin between the control and 1year storage group, although the $\mu$ TBS reduced over time. In addition, the failure modes of the $\mathrm{BF}$ specimens were not significantly different among the storage periods, although cohesive failure in resin (C-R) was the main failure mode, which increased over time. These results seem to indicate that for the tested onestep self-etch adhesives, the initial water sorption and solubility values are not related to the durability of the resin-dentin bond after long-term water storage.

With regards to the water sorption test in this study, the amount of water sorption rapidly increased in the beginning and then reached a plateau after 28 days of water storage. The initial water sorption of the one-step self-etch adhesives and subsequent reduction in mechanical properties may have resulted in poor load transference across the bonded interface. If the adhesive layer coupling the resin composite to the hybridized dentin reduces in stiffness and/or weakens, stress distribution across the bonded interface may be adversely affected possibly resulting in plastic deformation or debonding under loading. On the other hand, the solubility values in this study would mainly have been the result of a loss of mass by the elution of oligomers and monomers without hydrolytic degradation because of the short-term water immersion. However, solubility would increase over time due to hydrolysis after water immersion for a longer period ${ }^{29}$, 
in which there might be different effects in the one-step self-etch adhesives on their mechanical properties. There has been little research on the relationship between long-term water solubility and the mechanical properties of one-step self-etch adhesives. Further research is required to evaluate the effect of long-term water storage on the mechanical properties of one-step self-etch adhesives and their water sorption/solubility behaviors. Moreover, there might be other factors that affect the dentin bonding durability of one-step selfetch adhesives, such as the type of functional adhesive monomer, the composition of hydrophilic and hydrophobic monomers, filler content and the nanoleakage spaces within the hybrid layer and adhesive layer. Further research is also required to evaluate their effect on the dentin bonding durability of one-step self-etch adhesives.

\section{CONCLUSIONS}

Within the limitations of this study, the following conclusions can be drawn:

1. The water sorption and solubility values were significantly different among the three tested one-step self-etch adhesives.

2. The initial amount of water sorption and solubility did not affect the durability of the dentin bond of the tested one-step self-etch adhesives.

\section{ACKNOWLEDGMENTS}

This work was supported by the grant from the Japanese Ministry of Education, Global Center of Excellence (GCOE) Program, "International Research Center for Molecular Science in Tooth and Bone Diseases".

\section{REFERENCES}

1) Sano H, Takatsu T, Ciucchi B, Horner JA, Matthews WG, Pashley DH. Nanoleakage: leakage within the hybrid layer. Oper Dent 1995; 20: 18-25.

2) Tay FR, Hashimoto M, Pashley DH, Peters MC, Lai SC, Yiu CK, Cheong C. Aging affects two modes of nanoleakage expression in bonded dentin. J Dent Res 2003; 82: 537-541.

3) De Munck J, Van Meerbeek B, Yoshida Y, Inoue S, Vargas M, Suzuki K, Lanbrechts P, Vanherle G. Four-year water degradation of total-etch adhesives bonded to dentine. J Dent Res 2003; 82: 136-140.

4) Walker MP, Wang Y, Spencer P. Morphogical and chemical characterization of the dentin/resin cement interface produced with a self-etching primer. J Adhes Dent 2002; 4: 181-189.

5) Okuda M, Pereira PNR, Nakajima M, Tagami J, Pashley DH. Long-term durability of resin-dentine interface: nanoleakage vs. microtensile bond strength. Oper Dent 2002; 27: 289-296.

6) Hashimoto M, Fujita S, Kaga M, Yawaka Y. In vitro durability of one-bottle resin adhesives bonded to dentin. Dent Mater J 2007; 26: 677-686.

7) Torkabadi S, Nakajima M, Ikeda M, Foxton RM, Tagami J. Bonding durability of HEMA-free and HEMA-containing one-step adhesives to dentine surrounded by bonded enamel. J Dent 2008; 36: 80-86.

8) Foxton RM, Melo L, Stone DG, Pilecki P, Sherriff M, Watson TF. Long-term durability of one-step adhesivecomposite systems to enamel and dentin. Oper Dent 2008; 33: 651-657.

9) De Munck J, Van Landuyt K, Peumans M, Poitevin A, Lambrechts P, Braem M, Van Meerbeek B. A critical review of the durability of adhesion to tooth tissue: Methods and results J Dent Res 2005; 84: 118-132.

10) Pashley EL, Agee KA, Pashley DH, Tay FR. Effects of one versus two applications of an unfilled, all-in-one adhesive on dentine bonding. J Dent 2002; 30: 83-90.

11) Ito S, Hashimoto M, Wadgaonkar B, Svizero N, Carvalho RM, Yiu C, Rueggeberg FA, Foulger S, Saito T, Nishitani Y, Yoshiyama M, Tay FR, Pashley DH. Effects of resin hydrophilicity on water sorption and changes in modulus of elasticity. Biomaterials 2005; 26: 6449-6459.

12) Yiu CK, Pashley EL, Hiraishi N, King NM, Goracci C, Ferrari M, Carvalho RM, Pashley DH, Tay FR. Solvent and water retention in dental adhesive blends after evaporation. Biomaterials 2005; 26: 6863-6872.

13) Malacarne J, Carvalho RM, de Goes MF, Svizero N, Pashley DH, Tay FR, Yiu CK, Carrilho MR. Water sorption/solubility of dental adhesive resins. Dent Mater 2006; 22: 973-980.

14) Nishitani Y, Yoshiyama M, Hosaka K, Tagami J, Donnelly A, Carrilho M, Tay FR, Pashley DH. Use of Hoy's solubility parameters to predict water sorption/solubility of experimental primers and adhesives. Eur J Oral Sci 2007; 115: 81-86.

15) Yiu CK, King NM, Pashley DH, Suh BI, Carvalho RM, Carrilho MR, Tay FR. Effect of resin hydrophilicity and water storage on resin strength. Biomaterials 2004; 25: 5789-5796.

16) Tay FR, Pashley DH, Suh BI, Carvalho RM, Itthagarun A. Single-step adhesives are permeable membranes. J Dent 2002; 30: 371-382.

17) Paul SJ, Leach M, Rueggeberg FA, Pashley DH. Effect of water content on the physical properties of model dentine primer and bonding resins. J Dent 1999; 27: 209-214.

18) Hosaka K, Tagami J, Nishitani Y, Yoshiyama M, Carrilho M, Tay FR, Agee KA, Pashley DH. Effect of wet vs. dry testing on the mechanical properties of hydrophilic selfetching primer. Eur J Oral Sci 2007; 115: 239-245.

19) Nakaoki $Y$, Nikaido T, Pereira PN, Inokoshi S, Tagami J. Dimensional changes of demineralized dentin treated with HEMA primers. Dent Mater 2000; 16: 441-447.

20) Toledano M, Osorio R, de Leonardi G, Rosales-Leal JI, Ceballos L, Cabrerizo-Vilchez MA. Influence of self-etching primer on the resin adhesion to enamel and dentin. Am J Dent 2001; 14: 205-210.

21) Van Landuyt KL, De Munck J, Snauwaert J, Coutinho E, Poitevin A, Yoshida Y, Inoue E, Peumans M, Suzaki K, Lambrechts P, Van Meerbeek B. Monomer-solvent phase separation in one-step self-etching adhesives. J Dent Res 2005; 84: 183-188.

22) Monszner N, Salz U, Zimmermann J. Chemical aspects of self-etching enamel-dentin adhesives: a systematic review. Dent Mater 2005; 21: 895-910.

23) Spencer P, Wang Y. Adhesive phase separation at the dentin interface under wet bonding conditions. J Biomed Mater Res 2002; 62: 447-456.

24) Sideridou ID, Karabela MM, Vouvoudi ECh. Volumetric dimensional changes of dental light-cured dimethacrylate resins after sorption of water or ethanol. Dent Mater 2008; 24: 1131-1136.

25) Tay FR, Pashley DH, Yiu C, Cheong C, Hashimoto M, Itou K, Yoshiyama M, King NM. Nanoleakage types and potential implications: Evidence from unfilled and filled 
adhesives with the same resin composition. Am J Dent 2004; 17: 182-190.

26) Cadenaro M, Breschi L, Rueggeberg FA, Suchko M, Grodin E, Agee K, Di Lenarda R, Tay FR, Pashley DH. Effects of residual ethanol on the rate and degree of conversion of five experimental resins. Dent Mater 2009; 25: 621-628.

27) Ikeda T, De Munck J, Shirai K, Hikita K, Inoue S, Sano H, Lambrechts P, Van Meerbeek B. Effect of air-drying and solvent evaporation on the strength of HEMA-rich versus HEMA-free one-step adhesives. Dent Mater 2008; 24: 1316-
1323.

28) Bellenger V, Verdu J, Morel E. Structure-properties relationships for densely cross-linked epoxy-amine systems based on epoxide or amine mixtures. J Mater Sci 1989; 24: 63-68.

29) Reis AF, Giannini M, Pereira PN. Influence of water-storage time on the sorption and solubility behavior of current adhesives and primer/adhesive mixtures. Oper Dent 2007; 32: $53-59$. 